\title{
EDUCAÇÃO AMBIENTAL COMO ESTRATÉGIA DE REDUÇÃO DO ÍNDICE RESTO-INGESTA NO RESTAURANTE ACADÊMICO DE UMA INSTITUIÇÃO FEDERAL DE ENSINO NO MUNICÍPIO DE SOBRAL (CE)
}

\author{
Larissa Kelly Cunha dos Santos ${ }^{1}$ \\ Ana Lucia Feitoza Freire Pereira ${ }^{2}$ \\ Ana Carolina Rattacaso Marino de Mattos Albuquerque ${ }^{3}$
}

Resumo: As Unidades de Alimentação e Nutrição (UANs) têm relevante papel no desperdício de alimentos. O desperdício ocorre por meio da Sobra Limpa (SL), da Sobra Suja (SS) e do Resto-Ingesta. Este trabalho teve como objetivo a redução do resto-ingesta per capita, por meio da aplicação de estratégias de educação ambiental (EA) no restaurante acadêmico de uma instituição de ensino federal no município de Sobral/CE. A pesquisa deu-se em três fases: a $1^{\underline{a}}$ de observação, a $2^{\underline{a}}$ de aplicação das estratégias de EA e a $3^{\text {a }}$ de realização de um novo diagnóstico. Os resultados mostraram uma redução de 9,6g (18\%) na última etapa, refletindo assim a importância que práticas de EA em UANs têm para a minimização do desperdício de alimentos.

Palavras-Chave: Desperdício; Alimentos; Impacto Ambiental.

\footnotetext{
${ }^{1}$ Instituto Federal de Educação, Ciência e Tecnologia. E-mail: laryssacunha3108@gmail.com. Link para o Lattes: http://lattes.cnpq.br/4380125012879114

2 Instituto Federal de Educação, Ciência e Tecnologia. E-mail: anafeitoza@ifce.edu.br. Link para o Lattes: http://lattes.cnpq.br/3429649638783941

${ }^{3}$ Instituto Federal de Educação, Ciência e Tecnologia. E-mail: carolina.rattacaso@ifce.edu.br, Link para o Lattes: http://lattes.cnpq.br/1646674268293172
}

Revbea, São Paulo, V. 15, № 1: 310-327, 2020. 
Abstract: Food and Nutrition Units play an important role in food waste. Waste occurs through leftover clean, leftover dirty and Rest Ingest. This work aimed to reduce the rest-intake per capita, through the application of environmental education strategies in an academic restaurant of a federal educational institution in the municipality of Sobral/CE. The research occurred in three phases: the first observation, the second application of the environmental education strategies and the third was made a new diagnosis. The results showed a reduction of $9.6 \mathrm{~g}(18 \%)$ in the last stage, reflecting the importance that environmental education practices in food and nutrition units have for minimizing food waste.

Keywords: Waste; Foods; Environmental Impact.

\section{Introdução}

A alimentação é essencial ao ser humano de forma a garantir e suprir as necessidades básicas para a saúde e o bem-estar. Esse ato era realizado rotineiramente nas residências com os familiares, entretanto, no mundo moderno as ocupações profissionais e pessoais impossibilitam que essa tradição aconteça com mais frequência. Com isso houve a necessidade da criação de espaços voltados para a alimentação coletiva, que são as Unidades de Alimentação e Nutrição (UANs), as quais possibilitam a realização das refeições de forma mais prática, garantindo uma alimentação de qualidade e com um balanceamento nutricional satisfatório.

O Conselho Federal de Nutricionistas (CFN) define UAN como:

Unidade gerencial do serviço de nutrição e dietética onde são desenvolvidas todas as atividades técnico-administrativas necessárias para a produção de alimentos e refeições, até a sua distribuição para coletividades sadias e enfermas, além da atenção nutricional a pacientes na internação e em ambulatórios (RESOLUÇÃO CFN N³80, 2005, p. 10).

As UANs são grandes produtoras de alimentos e por isso têm contribuição significativa para a perda e desperdício dos mesmos, havendo uma grande diferença entre o que significam os termos desperdício e perda, que podem ser naturalmente confundidos, sendo de extrema importância que se tenha o conhecimento do que as difere (FAO, 2013).

A palavra perda representa uma diminuição dos alimentos que são disponibilizados para o consumo humano, por não apresentarem um aspecto qualitativo apropriado, sendo resultado de falhas na cadeia produtiva dos alimentos, acontecendo principalmente nas etapas de produção, pós-colheita e processamento. Já o que chamamos de desperdício demonstra o ato de jogar fora o alimento que está próprio para o consumo, de forma intencional, estando 
relacionado ao comportamento dos indivíduos, refletindo a falta de informação e consciência que as pessoas têm em relação ao consumo dos alimentos (FAO, 2013).

O desperdício acontece por meio de sobras e restos. Quando o alimento é produzido e não consumido, sem ser destinado a distribuição, é chamado de sobra limpa (SL), podendo ser reaproveitado de maneira correta. Já quando ocorre sua produção e distribuição, porém não é servido ao comensal é chamado de sobra suja (SS), e não pode ser reaproveitado. Resto-ingesta é aquele deixado no prato pelos comensais e que tem como destino o lixo.

As sobras e restos alimentares estão diretamente ligados aos custos da UAN, assim, evitando-se o desperdício ocorre um melhor gerenciamento de recursos do estabelecimento (MULLER, 2008).

O desperdício de alimentos é um problema mundial e causa diversos impactos, podendo ser de cunho ambiental, social e econômico. Afeta de maneira significativa a qualidade do ambiente, consequentemente prejudica a saúde e bem-estar da população.

A prática do consumismo exagerado também afeta aos alimentos, ou seja, adquire-se além do que é preciso e dessa forma, os alimentos não consumidos vão para o lixo, ocasionando uma diversidade de impactos negativos (RUIZ LANNA, 2016).

Alguns desses impactos podem ser observados no solo e água utilizados no cultivo e preparo dos alimentos que não serão consumidos. A pegada de carbono ao longo de toda a cadeia produtiva dos alimentos é responsável pela emissão de 3,3 bilhões de toneladas por ano (FAO, 2013), tornando o desperdício de alimentos $\circ 3^{\circ}$ maior responsável pela contribuição de emissões de Gases de Efeito Estufa (GEE).

De acordo com a Organização das Nações Unidas para a Alimentação e a Agricultura (FAO) (2013), no mundo, anualmente, são desperdiçados 1,3 bilhão de toneladas de alimentos, ou mesmo se perde ao longo de sua cadeia produtiva, representando $30 \%$ de todo alimento que é produzido por ano no planeta. Onde o desperdício corresponde a $46 \%$ da quantidade de comida que vai para o lixo, enquanto as perdas, que acontecem geralmente nas etapas de produção, armazenamento e transporte equivalem a $54 \%$ deste total.

A segurança alimentar é um fator social preocupante, pois enquanto existem milhares de pessoas sofrendo com a falta de alimentação, 0 desperdício acontece de maneira desenfreada. Impactos econômicos também são visíveis, por meio dos gastos com comidas que serão jogadas fora.

Através da avaliação das sobras e restos de alimentos dentro de uma unidade é possível buscar e obter redução no desperdício de alimentos, e por mudanças no planejamento em relação às refeições distribuídas. Também é importante conhecer os gostos alimentares dos comensais, buscando sua satisfação e a criação de medidas estratégicas para praticar a educação 
ambiental. Entretanto, o correto é que o comensal sirva-se somente daquilo que vai consumir.

A educação ambiental é uma ferramenta de fundamental importância para incorporar no indivíduo a preocupação com a sustentabilidade e construir uma relação harmônica entre o homem e meio ambiente.

Segundo a Política Nacional de Educação Ambiental (PNEA), entendese por educação ambiental:

Os processos por meio dos quais o indivíduo e a coletividade constroem valores sociais, conhecimentos, habilidades, atitudes e competências voltadas para a conservação do meio ambiente, bem de uso comum do povo, essencial á sadia qualidade de vida e a sua sustentabilidade (LEI No 9.795, 1999, p.1).

Faz-se necessário, a criação de atividades contra o desperdício de alimentos, incentivando a sensibilização e conscientização das pessoas em relação a essa problemática, levando informação e conhecimento sobre a causa, sendo essencial sua efetiva continuidade para melhores resultados.

O presente trabalho teve como objetivo a redução do Resto-Ingesta per capita, por meio da aplicação de estratégias de educação ambiental contra o desperdício de alimentos em um restaurante acadêmico de uma instituição federal de ensino no município de Sobral - CE.

\section{Metodologia}

\section{Área de estudo}

A pesquisa foi realizada no Restaurante Acadêmico (RA), localizado dentro de uma Instituição Federal de Ensino, na cidade de Sobral-Ceará. O espaço de funcionamento do RA pertence à Instituição de Ensino (Figura 1).

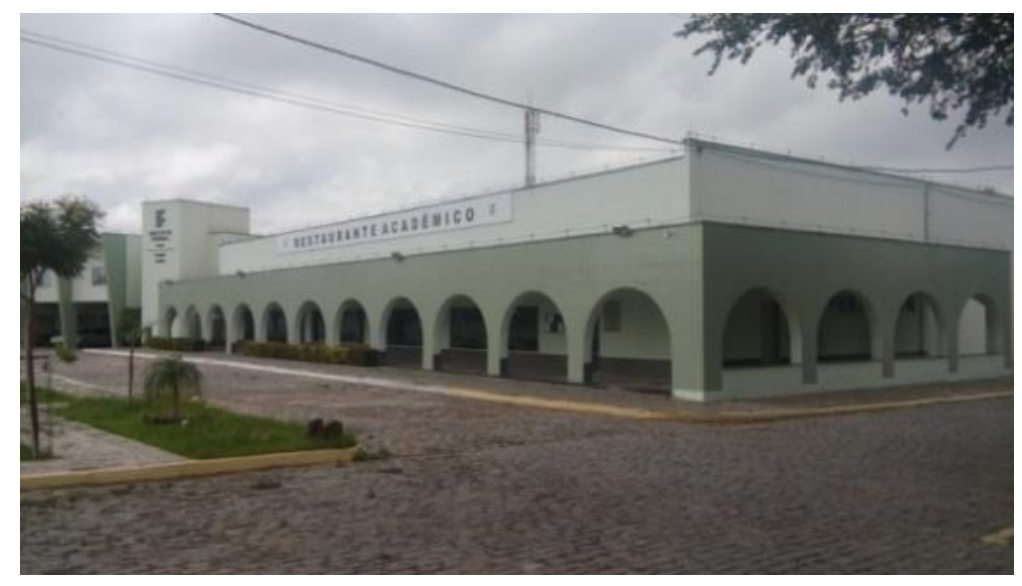

Figura 1: Restaurante acadêmico.

Fonte: Autor (2018). 
A empresa atuante dentro do RA é terceirizada, ou seja, é uma entidade contratada que presta serviços para determinado órgão, realizando o preparo e servindo as refeições. A equipe do RA é formada por duas nutricionistas, sendo uma da empresa terceirizada e a outra da Instituição de Ensino; uma tecnóloga em Alimentos; três cozinheiros; um açougueiro e cinco auxiliares de serviços gerais.

O cardápio e composto por arroz branco e integral, feijão, guarnição, salada, vegetariano e duas opções principais. Também é servido suco e uma opção de sobremesa (fruta ou doce).

O horário de funcionamento do RA é de $07 \mathrm{~h} 30 \mathrm{~min}$ às $22 \mathrm{~h} 00 \mathrm{~min}$ para os funcionários iniciarem e terminarem suas tarefas (preparo das refeições, limpeza do ambiente, etc.), no entanto, é aberto para servir as refeições aos comensais a partir das $10 \mathrm{~h} 30 \mathrm{~min}$ da manhã às $13 \mathrm{~h} 30 \mathrm{~min}$ da tarde para 0 horário de almoço e das $17 \mathrm{~h} 30 \mathrm{~min}$ da tarde às $20 \mathrm{~h} 30 \mathrm{~min}$ da noite para o jantar. A maioria do público que frequenta o restaurante diariamente (segunda a sexta-feira) são os alunos da Instituição de Ensino, mas o RA é aberto também ao público externo e recebe diversos visitantes, tendo um movimento diário de cerca de 500 pessoas.

\section{Procedimentos metodológicos}

\section{Classificação da Pesquisa}

Segundo Gil (1996) e Silva (2004), esta pesquisa pode ser classificada da seguinte forma:

- Quanto à natureza: Trata-se de uma pesquisa aplicada, pois gera conhecimentos para aplicação prática, dirigida a soluções de problemas específicos.

- Quanto à forma de abordagem: qualitativa e quantitativa.

- Quanto aos objetivos: exploratória, descritiva e explicativa.

- Quanto aos procedimentos técnicos: pesquisa experimental e um estudo de caso.

\section{Delineamento da pesquisa}

A pesquisa foi realizada entre os meses de Novembro de 2017 à Março de 2018, no turno do almoço, sendo dividida em três etapas: 1) diagnóstico da situação atual da UAN; 2) Aplicação de Estratégias de Educação Ambiental para a redução do índice resto-ingesta; 3) Avaliação dos resultados, conforme Tabela 1. 
Tabela 1: Detalhamento das etapas.

\begin{tabular}{|c|c|c|}
\hline Etapas & Período & Intervenções realizadas \\
\hline $1^{\mathrm{a}}$ & $13 / 11$ a $14 / 12 / 2017$ & $\begin{array}{l}\text { - Observação do comportamento dos comensais; } \\
\text { - Orientação aos comensais sobre o descarte correto dos } \\
\text { resíduos; } \\
\text { - Colocação de cartazes informativos para o descarte } \\
\text { correto dos resíduos; }\end{array}$ \\
\hline $2^{\mathbf{a}}$ & $29 / 01$ a $02 / 03 / 2018$ & $\begin{array}{l}\text { - 29/01 a 02/02: Implantação do desperdiçômetro e dos } \\
\text { cartazes; } \\
\text { - 05/02 a 09/02: Demonstração de alimentos crus para } \\
\text { representar o desperdício por semana, desperdiçômetro e } \\
\text { cartazes; } \\
\text { - 19/02 a 23/02: Abordagem aos comensais antes de } \\
\text { servirem-se, demonstração de alimentos crus, } \\
\text { desperdiçômetro e cartazes; } \\
\text { - 26/02 a 02/03: Adesivagem e entrega de bombons para } \\
\text { os comensais com o prato limpo, folhetos informativos nas } \\
\text { mesas do RA, demonstração de alimentos crus, } \\
\text { desperdiçômetro e cartazes; }\end{array}$ \\
\hline $3^{\mathrm{a}}$ & 05/03 a 06/04/2018 & $\begin{array}{l}\text { - Novo diagnóstico sobre a situação do resto-ingesta. } \\
\text { - Coleta dos dados para a avaliação da pesquisa. }\end{array}$ \\
\hline
\end{tabular}
Fonte: Autor (2018).

\section{1aㅡ etapa: Diagnóstico da situação atual da UAN}

Ocorreu no período de Novembro à Dezembro de 2017, a fim de obterse um conhecimento mais detalhado quanto ao seu funcionamento em geral. Nessa etapa foi possível identificar o comportamento dos comensais, o modo como os resíduos são separados, através da observação do descarte dos restos na hora da devolução das bandejas, pois nesse momento é feita a separação, além dos descartáveis, entre as cascas e ossos e o restante dos orgânicos para obtenção do peso do desperdício, sem a interferência destes. Para isso foram colocados cartazes permitissem identificar as lixeiras e com isso auxiliar os comensais para a separação correta, como mostra a Figura 2.

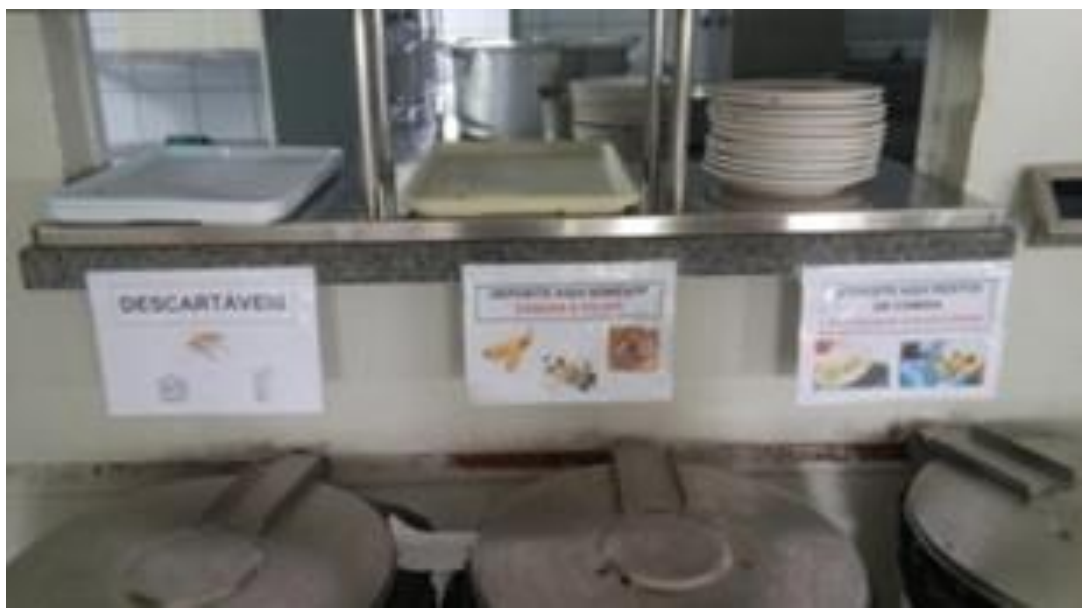

Figura 2: Local de descarte de resíduos com os cartazes indicativos.

Fonte: Autor (2018). 
Houve o acompanhamento da pesagem das sobras (limpa e suja) e do resto-ingesta (Figura 3), sendo feita a separação manual das cascas e ossos para não interferir no peso exato do que foi realmente desperdiçado, pois estes não são classificados como desperdício. Foi feito também o preenchimento de planilhas do RA para a tabulação dos dados que servem para auxiliar o controle e planejamento da empresa e demonstração aos comensais do que é desperdiçado diariamente.

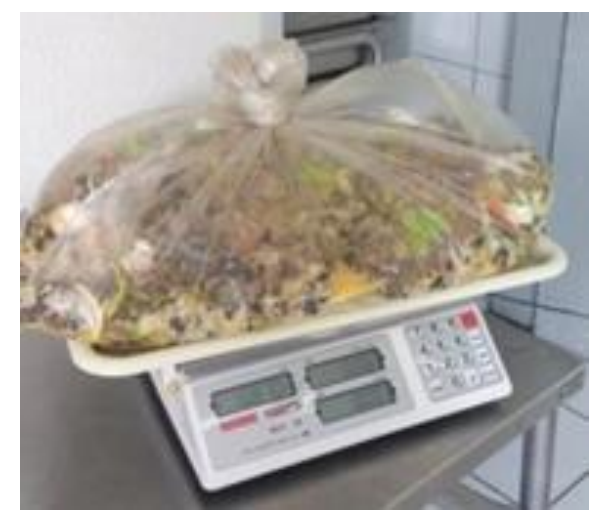

Figura 3: Acompanhamento da pesagem dos resíduos orgânicos.

Fonte: Autor (2018).

2ª etapa: Aplicação de Estratégias de Educação Ambiental para a redução do índice resto-ingesta

No período de Janeiro à Março de 2018, foi executada a segunda etapa da pesquisa, onde foram aplicadas as estratégias de Educação Ambiental: cartazes com frases educativas e de sensibilização (Figura 4) e demonstração de alimentos crus (Figura 5), com o objetivo de causar impacto aos comensais sobre o desperdício diário do RA, auxiliado também por um "Desperdiçômetro" (Figura 6) que mostra a quantificação em quilogramas do total de resto-ingesta por dia.

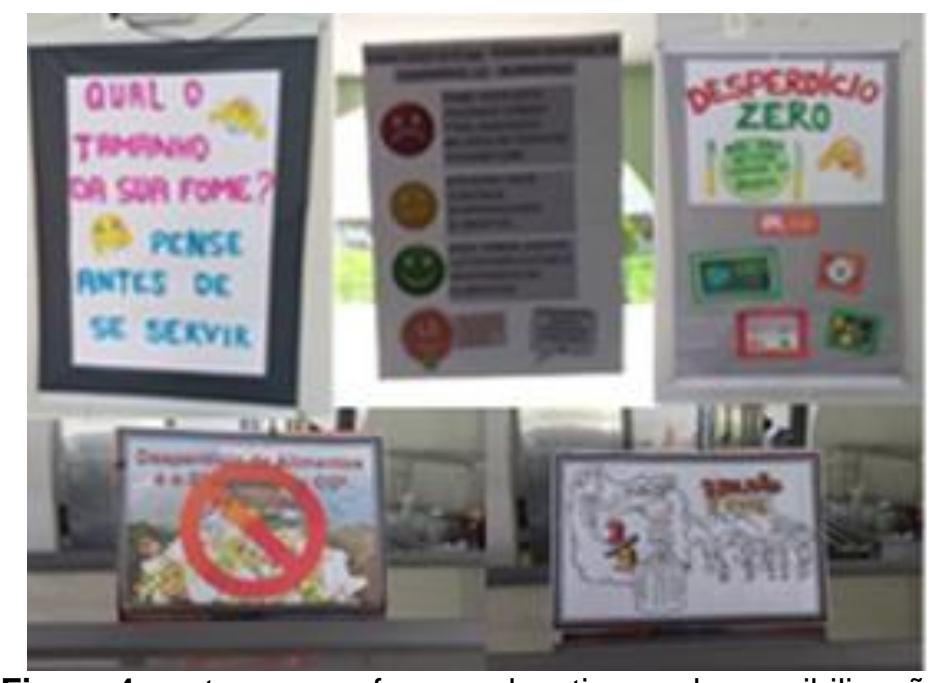

Figura 4: cartazes com frases educativas e de sensibilização. Fonte: Autor (2018). 


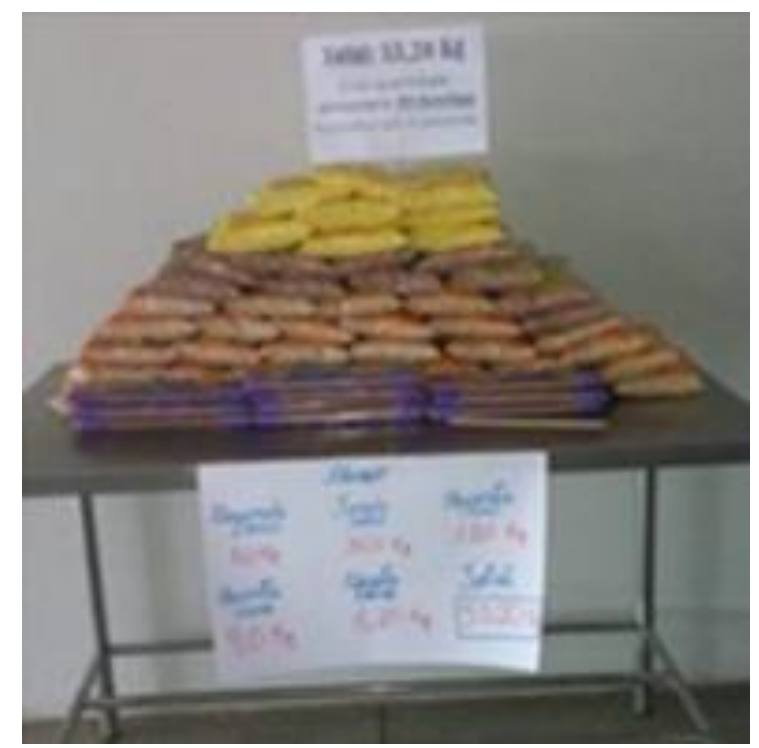

Figura 5: Demonstração de alimentos desperdiçados por semana.

Fonte: Autor (2018).

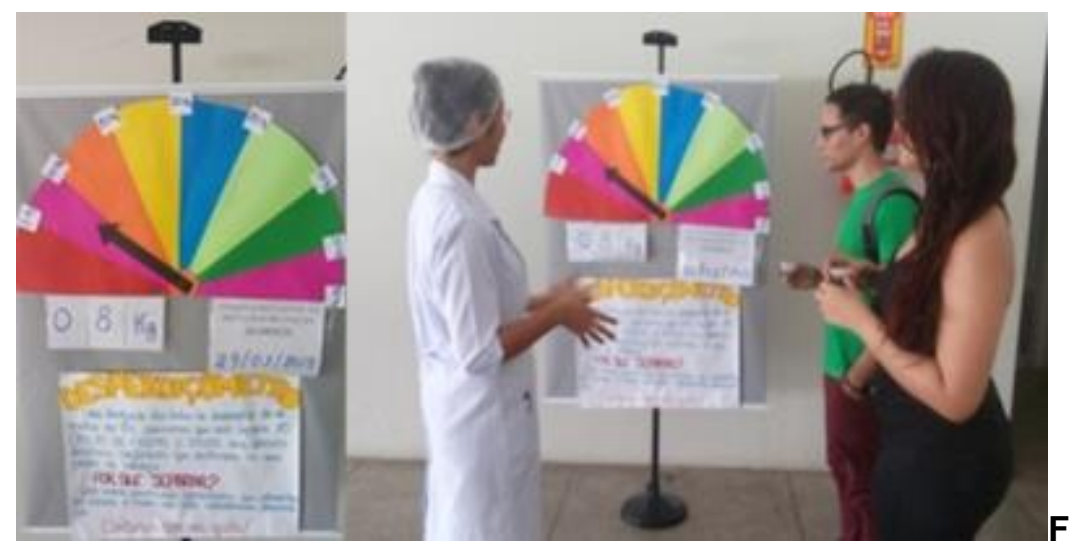

Figura 6: Desperdiçômetro.

Fonte: Autor (2018).

Outra ferramenta utilizada foi a abordagem aos comensais, na chegada a bancada para se servirem, efetuando uma breve conversa sobre a importância de não desperdiçar os alimentos, com a finalidade de praticar a sensibilização ambiental, mostrando para eles a influência que se pode ter em relação ao desperdício no momento de servir-se. Foi feita também a ação de adesivagem e entrega de bombons de chocolate aos comensais no ato de devolução dos pratos e bandejas, adesivando somente aqueles que estivessem com o prato limpo (Figura 7), com intuito de incentivá-los a consumirem tudo aquilo que colocam no prato, evitando o desperdício. Ainda foram colocados folhetos informativos nas mesas do RA sobre o desperdício de alimentos e os impactos causados (Figura 8). 


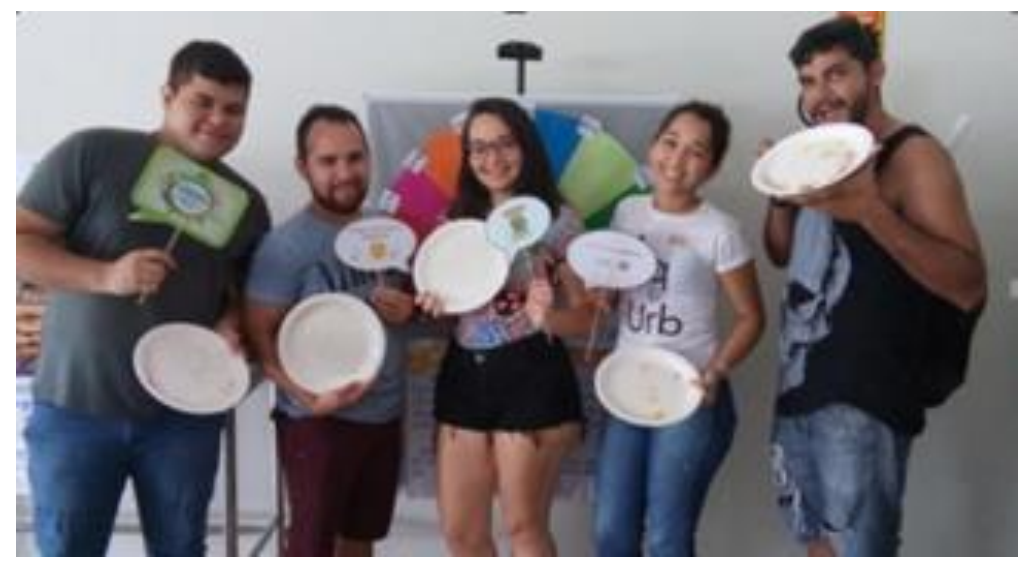

Figura 7: Campanha de adesivagem e entrega de bombons. Fonte: Autor (2018).

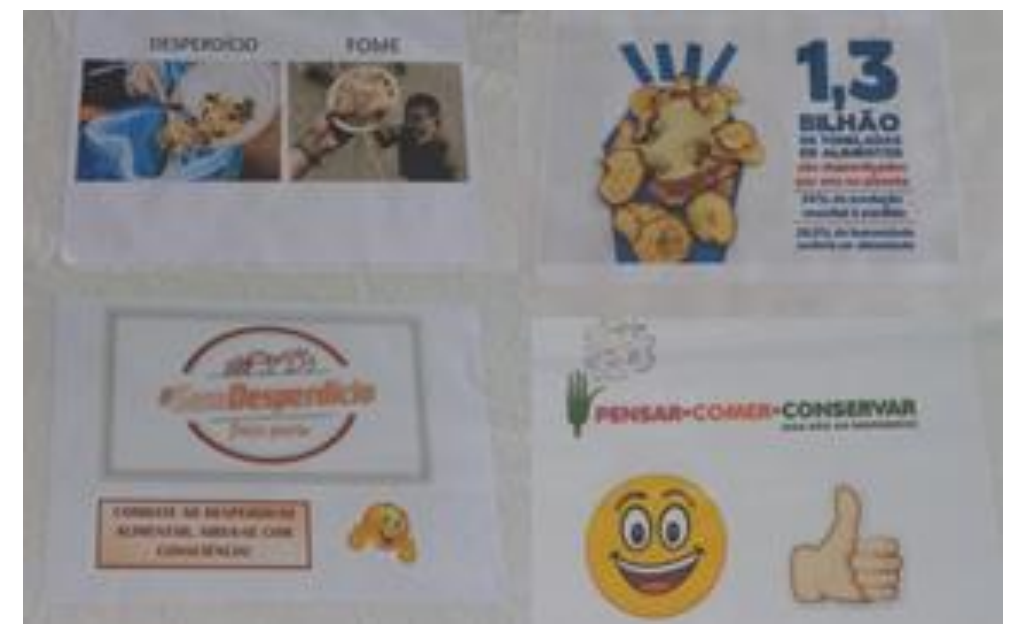

Figura 8: Folhetos informativos das mesas do RA.

Fonte: Autor (2018).

$3^{a}$ etapa: A terceira e última etapa realizada nos meses de março a maio de 2018, consistiu de um novo diagnóstico da unidade, destacando em que situação se encontra e quais os resultados obtidos após a aplicação das ações de Educação Ambiental voltadas a redução do índice resto-ingesta.

As equações utilizadas para a obtenção dos resultados do índice de resto-ingesta, consumo per capita, per capita de resto-ingesta, número de pessoas que poderiam ser alimentadas e índice de redução do resto-ingesta (\%), estão listadas na Tabela 2. 
Tabela 2: Equações utilizadas na pesquisa.

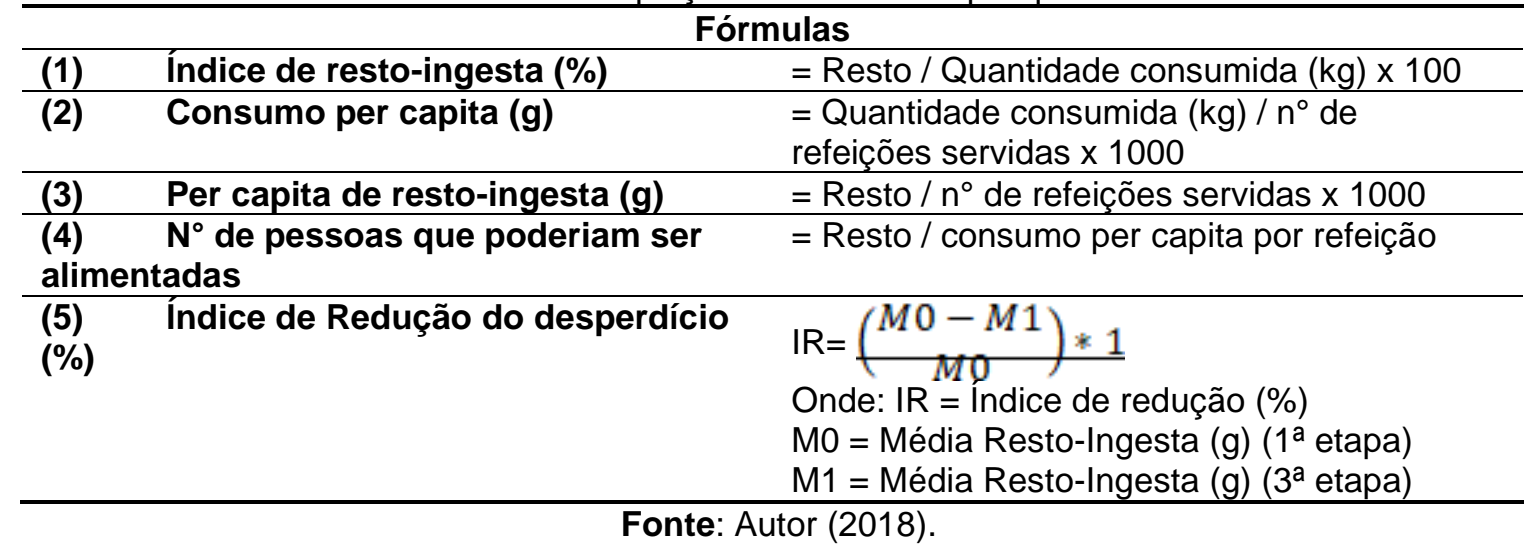

\section{Resultados e discussões}

Para se obter o resultado real do desperdício foi necessário separar os restos de comida das cascas e ossos, pois estes não contam como desperdício e foi identificada a falta de interesse dos comensais em separar os resíduos na hora do descarte, da maneira correta nas lixeiras. Através do processo de sensibilização realizado sobre a importância dessa atitude e ao serem melhor identificadas as lixeiras, houve mudança significativa na separação dos resíduos. A Figura 9 e Tabela 3 e apresentam os dados coletados na primeira etapa.

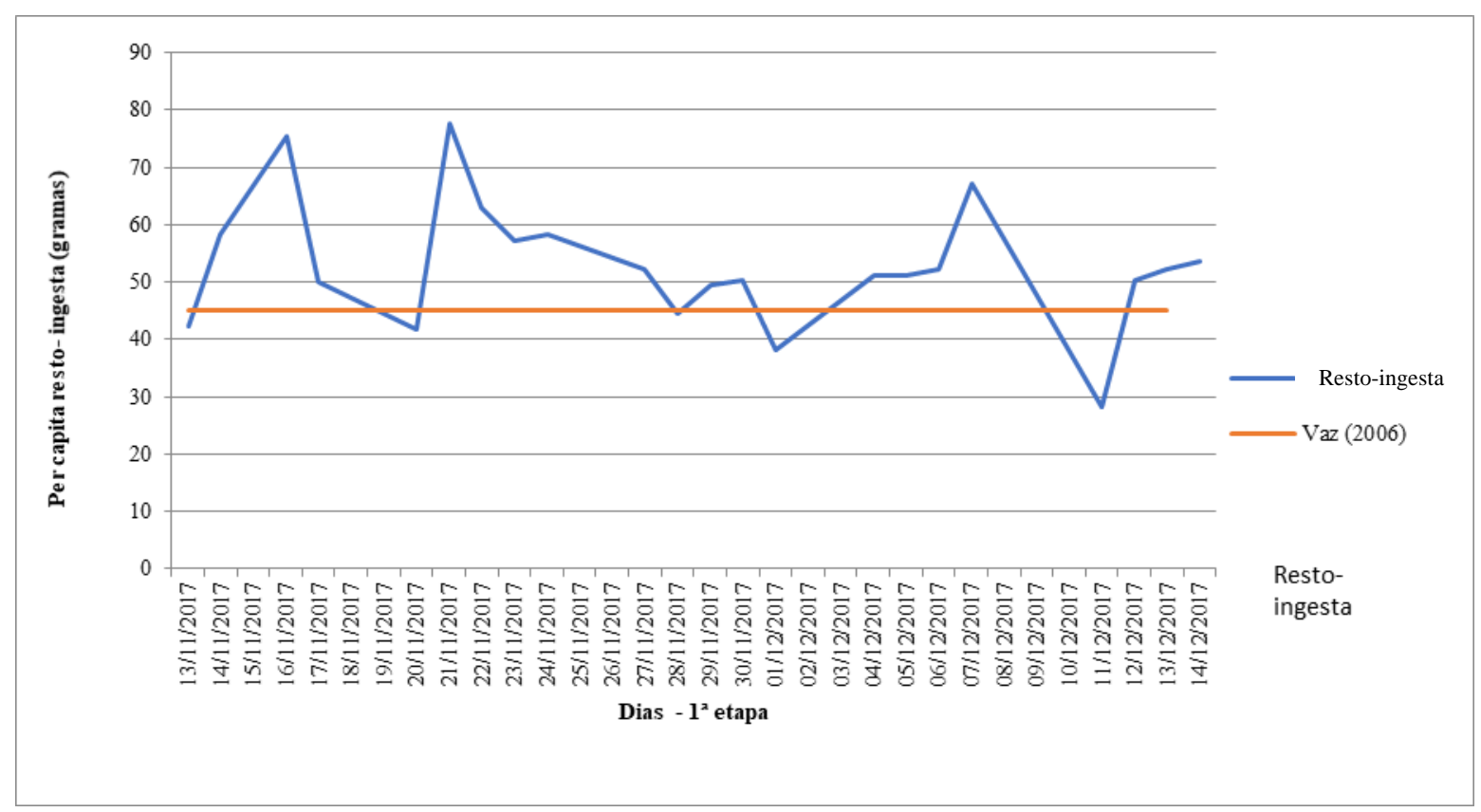

Figura 9: Per capita resto-ingesta - $1^{\circ}$ Etapa.

Fonte: Autor (2018).

Revbea, São Paulo, V. 15, № 1: 310-327, 2020.

revista brasileira educação ambiental 
Tabela 3: $1^{\circ}$ etapa - Observação.

\begin{tabular}{|c|c|c|c|c|c|}
\hline Data & $\begin{array}{c}\mathrm{n}^{\circ} \text { de refeições } \\
\text { servidas }\end{array}$ & $\begin{array}{c}\text { Resto- ingesta } \\
(\mathrm{kg})\end{array}$ & $\begin{array}{c}\text { Per capita } \\
\text { resto- ingesta (g) }\end{array}$ & $\begin{array}{l}\text { Consumo per } \\
\text { capita (g) }\end{array}$ & $\begin{array}{l}\text { Índice resto- } \\
\text { ingesta (\%) }\end{array}$ \\
\hline $13 / 11 / 2017$ & 257 & 10,85 & 42,2 & 393 & 10,74 \\
\hline $14 / 11 / 2017$ & 362 & 21,10 & 58,3 & 488 & 11,95 \\
\hline $15 / 11 / 2017$ & & & FERIADO & & \\
\hline $16 / 11 / 2017$ & 272 & 20,50 & 75,4 & 669 & 11,59 \\
\hline $17 / 11 / 2017$ & 280 & 14,02 & 50,1 & 589 & 8,50 \\
\hline 20/11/2017 & 221 & 9,24 & 41,8 & 581 & 7,19 \\
\hline $21 / 11 / 2017$ & 272 & 21,10 & 77,6 & 669 & 11,59 \\
\hline $22 / 11 / 2017$ & 374 & 23,60 & 63,1 & 612 & 9,23 \\
\hline $23 / 11 / 2017$ & 292 & 16,70 & 57,2 & 630 & 9,07 \\
\hline $24 / 11 / 2017$ & 237 & 13,84 & 58,4 & 448 & 13,04 \\
\hline $27 / 11 / 2017$ & 227 & 11,84 & 52,1 & 541 & 9,64 \\
\hline $28 / 11 / 2017$ & 312 & 13,91 & 44,6 & 847 & 5,26 \\
\hline $29 / 11 / 2017$ & 326 & 16,10 & 49,4 & 695 & 7,10 \\
\hline $30 / 11 / 2017$ & 266 & 13,37 & 50,3 & 645 & 7,80 \\
\hline $01 / 12 / 2017$ & 265 & 10,12 & 38,2 & 556 & 6,86 \\
\hline $04 / 12 / 2017$ & 219 & 11,21 & 51,2 & 526 & 9,72 \\
\hline 05/12/2017 & 309 & 15,80 & 51,1 & 486 & 10,52 \\
\hline $06 / 12 / 2017$ & 328 & 17,10 & 52,1 & 610 & 8,95 \\
\hline $07 / 12 / 2017$ & 224 & 15,00 & 67,0 & 521 & 12,86 \\
\hline 08/12/2017 & & & FERIADO & & \\
\hline $11 / 12 / 2017$ & 332 & 9,33 & 28,1 & 628 & 6,40 \\
\hline 12/12/2017 & 317 & 15,90 & 50,2 & 551 & 9,10 \\
\hline 13/12/2017 & 345 & 18,00 & 52,2 & 554 & 9,42 \\
\hline $14 / 12 / 2017$ & 244 & 13,10 & 53,7 & 622 & 11,86 \\
\hline MÉDIA & 285,5 & 15,08 & 52,9 & 584,6 & 9,5 \\
\hline
\end{tabular}

Fonte: Autor (2018).

Conforme a Tabela 3 verificou-se que nos dias 13, 20, 28 de novembro e 01 e 11 de dezembro, foram obtidos os valores de resto-ingesta per capita de: 42,$2 ; 41,8 ; 44,6 ; 38,2$ e 28,1 gramas, respectivamente. Dentre os vinte e dois analisados, estiveram de acordo com o que sugere ser aceitável por Vaz (2006) que é de até $45 \mathrm{~g}$, somente cinco dias, os demais se encontraram acima deste valor, como pode ser observado na Figura 9, que representa essa variação. A média do índice de resto-ingestão (\%) nesse período foi de 9,5\%. Castro (2003) considera como aceitável o índice resto-ingestão de até $10 \%$, estando a UAN em estudo de acordo com o que recomenda esse autor.

Durante a aplicação das estratégias, por meio do diálogo com os comensais, após obterem um conhecimento sobre os impactos que 0 desperdício de alimentos causa, através das ações que foram aplicadas no RA contra o desperdício, pôde-se perceber a conscientização dos mesmos em 
relação a servir-se de maneira adequada com o que está disposto a consumir, sendo identificada a preocupação por parte deles, de não jogar comida fora.

Na segunda etapa, Aplicação de Estratégias de Educação Ambiental, foi possível perceber a redução do resto-ingesta per capita, conforme mostra a tabela 4. Obteve-se uma redução considerável da média per capita de restoingesta que na $1^{\text {a }}$ etapa foi de $52,9 \mathrm{~g}$ para $43,1 \mathrm{~g}$ na $2^{\underline{a}}$ etapa. Houve uma diminuição da média de resto-ingesta per capita de $9,8 \mathrm{~g}$, o equivalente $18 \%$ de redução. Dentre os vinte e dois da pesquisa na $2^{\text {a }}$ etapa, 15 dias se mantiveram dentro do aceitável por Vaz (2006), que é de até $45 \mathrm{~g}$. Apenas seis dias permaneceram acima do recomendado pela literatura. A Figura 10 mostra o comportamento de redução do per capita resto-ingestão durante essa etapa. Pode-se ressaltar o dia 28 de fevereiro com a menor per capita, que foi de $25,5 \mathrm{~g}$, dia este que houve a entrega de adesivos e bombons para os comensais com o prato limpo, assim demonstrando a eficiência da aplicação de estratégias de sensibilização com foco na redução do desperdício de alimentos. A média do índice de resto-ingestão (\%) nesse período foi de 7,1\%, havendo uma redução de $2,4 \%$ em relação ao mês anterior, mostrado na Tabela 4, estando de acordo com o que recomenda Castro (2003) que é de até $10 \%$ em coletividades sadias.

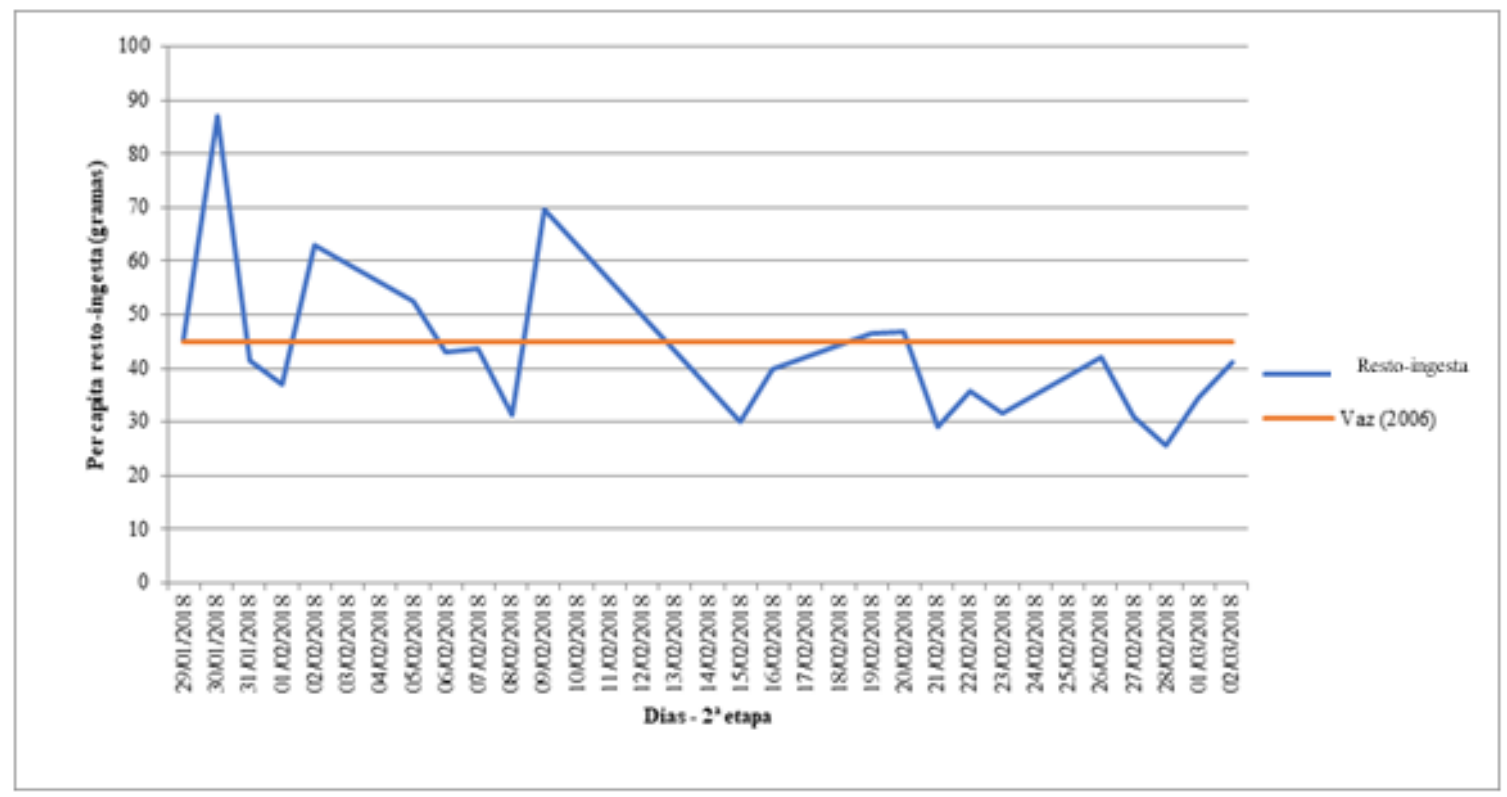

Figura 10: Per capita resto-ingesta $-2^{\circ}$ etapa.

Fonte: Autor (2018). 
Tabela 4: $2^{\circ}$ etapa - aplicação das estratégias.

\begin{tabular}{|c|c|c|c|c|c|}
\hline Data & $\begin{array}{c}\mathrm{n}^{\circ} \text { de refeições } \\
\text { servidas }\end{array}$ & $\begin{array}{c}\text { Resto- ingesta } \\
\text { (kg) }\end{array}$ & $\begin{array}{c}\text { Per capita } \\
\text { resto- ingesta (g) }\end{array}$ & $\begin{array}{c}\text { Consumo per } \\
\text { capita (g) }\end{array}$ & $\begin{array}{l}\text { İ́ndice resto- } \\
\text { ingesta (\%) }\end{array}$ \\
\hline 29/01/2018 & 176 & 7,95 & 45,2 & 623 & 7,13 \\
\hline $30 / 01 / 2018$ & 184 & 16,00 & 87,0 & 795 & 10,94 \\
\hline $31 / 01 / 2018$ & 291 & 12,10 & 41,6 & 536 & 7,75 \\
\hline 01/02/2018 & 233 & 8,60 & 36,9 & 650 & 5,68 \\
\hline 02/02/2018 & 130 & 8,20 & 63,1 & 956 & 6,60 \\
\hline 05/02/2018 & 198 & 10,40 & 52,5 & 521 & 10,09 \\
\hline 06/02/2018 & 301 & 12,90 & 42,9 & 574 & 7,46 \\
\hline 07/02/2018 & 317 & 13,90 & 43,8 & 495 & 8,86 \\
\hline 08/02/2018 & 253 & 7,90 & 31,2 & 486 & 6,42 \\
\hline 09/02/2018 & 161 & 11,20 & 69,6 & 781 & 8,90 \\
\hline $\begin{array}{c}12 / 02 / 2018 \\
a \\
14 / 02 / 2018\end{array}$ & & & FERIADO & & \\
\hline $15 / 02 / 2018$ & 172 & 5,20 & 30,2 & 675 & 4,48 \\
\hline $16 / 02 / 2018$ & 190 & 7,60 & 40,0 & 558 & 7,17 \\
\hline 19/02/2018 & 235 & 10,90 & 46,4 & 612 & 7,58 \\
\hline 20/02/2018 & 326 & 15,30 & 46,9 & 571 & 8,22 \\
\hline $21 / 02 / 2018$ & 308 & 9,00 & 29,2 & 542 & 5,40 \\
\hline 22/02/2018 & 258 & 9,20 & 35,7 & 679 & 5,25 \\
\hline $23 / 02 / 2018$ & 247 & 7,80 & 31,6 & 512 & 6,17 \\
\hline $26 / 02 / 2018$ & 187 & 7,90 & 42,2 & 618 & 6,83 \\
\hline $27 / 02 / 2018$ & 310 & 9,60 & 31,0 & 427 & 7,25 \\
\hline $28 / 02 / 2018$ & 329 & 8,40 & 25,5 & 460 & 5,54 \\
\hline 01/03/2018 & 234 & 8,10 & 34,6 & 677 & 5,11 \\
\hline 02/03/2018 & 234 & 9,60 & 41,0 & 546 & 7,52 \\
\hline MÉDIA & 239,7 & 9,9 & 43,1 & 604,3 & 7,1 \\
\hline
\end{tabular}

Fonte: Autor (2018).

$\mathrm{Na}$ terceira e última etapa, foi realizado um novo diagnóstico para observar o efeito que a aplicação das estratégias de educação ambiental teve para a redução do resto-ingesta per capita. Pôde-se perceber que a média per capita de resto-ingesta após a aplicação das estratégias, foi de $43,3 \mathrm{~g}$, havendo um aumento de 0,2 gramas em relação a $2^{\text {a }}$ etapa que foi de 43,1 . A média do índice de resto-ingestão (\%) nesse período foi de 7,4\%, havendo um aumento pequeno em relação a etapa anterior que foi de $0,3 \%$. Dentre os vinte e dois da pesquisa na $3^{\text {a }}$ etapa, 15 dias se mantiveram dentro do aceitável por Vaz (2006), que é de até $45 \mathrm{~g}$, como pode ser visto na Figura 11. Apenas seis dias permaneceram acima do recomendado pela literatura (Tabela 5). A média do índice de resto-ingestão (\%) nesse período também se manteve dentro do aceitável pela literatura. 


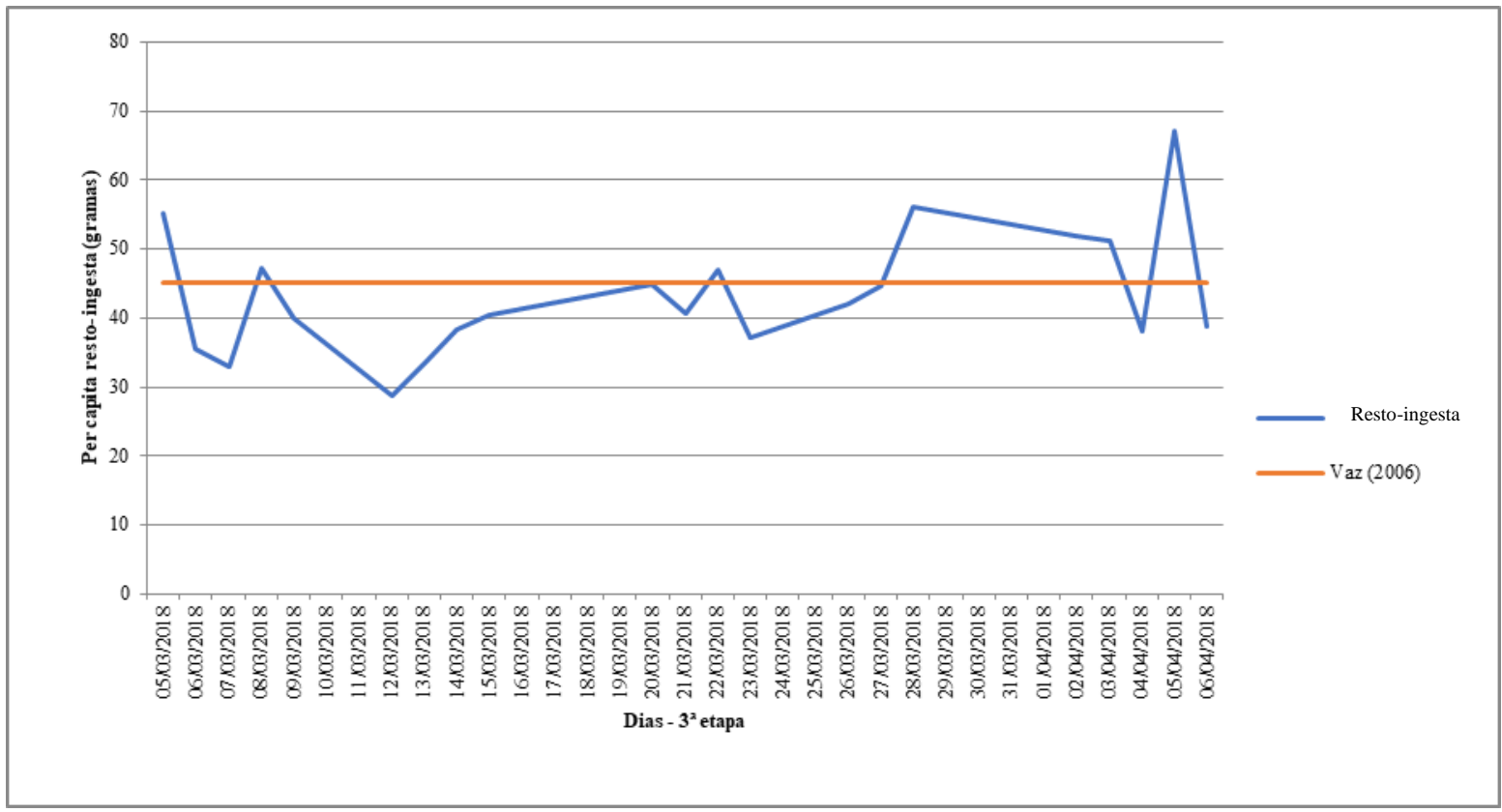

Figura 11: Per capita resto-ingesta - $3^{\circ}$ etapa.

Fonte: Autor (2018).

Tabela 5: $3^{\circ}$ etapa - Novo diagnóstico.

\begin{tabular}{cccccc}
\hline Data & $\begin{array}{c}\mathbf{n}^{\circ} \text { de refeições } \\
\text { servidas }\end{array}$ & $\begin{array}{c}\text { Resto- ingesta } \\
(\mathbf{k g})\end{array}$ & $\begin{array}{c}\text { Per capita } \\
\text { resto- ingesta (g) }\end{array}$ & $\begin{array}{c}\text { Consumo per } \\
\text { capita (g) }\end{array}$ & $\begin{array}{c}\text { índice resto- } \\
\text { ingesta (\%) }\end{array}$ \\
\hline $05 / 03 / 2018$ & 210 & 11,60 & 55,2 & 580 & 9,53 \\
\hline $06 / 03 / 2018$ & 299 & 10,60 & 35,5 & 564 & 6,29 \\
\hline $07 / 03 / 2018$ & 331 & 10,90 & 32,9 & 469 & 7,02 \\
\hline $08 / 03 / 2018$ & 242 & 11,40 & 47,1 & 704 & 6,69 \\
\hline $09 / 03 / 2018$ & 240 & 9,60 & 40,0 & 590 & 6,78 \\
\hline $12 / 03 / 2018$ & 203 & 5,80 & 28,6 & 759 & 3,77 \\
\hline $13 / 03 / 2018$ & 312 & 10,40 & 33,3 & 585 & 5,70 \\
\hline $14 / 03 / 2018$ & 329 & 12,59 & 38,3 & 513 & 7,46 \\
\hline $15 / 03 / 2018$ & 252 & 10,20 & 40,5 & 524 & 7,72 \\
\hline $16 / 03 / 2018$ & 266 & 11,02 & 41,4 & 604 & 6,86 \\
\hline $19 / 03 / 2018$ & & & FERIADO & & \\
\hline $20 / 03 / 2018$ & 306 & 13,70 & 44,8 & 487 & 9,20 \\
\hline $21 / 03 / 2018$ & 320 & 13,00 & 40,6 & 548 & 7,42 \\
\hline $22 / 03 / 2018$ & 270 & 12,70 & 47,0 & 533 & 8,83 \\
\hline $23 / 03 / 2018$ & 231 & 8,60 & 37,2 & 588 & 6,33 \\
\hline $26 / 03 / 2018$ & 211 & 8,87 & 42,0 & 614 & 6,84 \\
\hline $27 / 03 / 2018$ & 298 & 13,30 & 44,6 & 570 & 7,83 \\
\hline & & & & & Continua... \\
\hline
\end{tabular}

Revbea, São Paulo, V. 15, № 1: 310-327, 2020. 
,,,continuação.

\begin{tabular}{cccccc}
\hline Data & $\begin{array}{c}\mathbf{n}^{\circ} \text { de refeições } \\
\text { servidas }\end{array}$ & $\begin{array}{c}\text { Resto- ingesta } \\
(\mathbf{k g})\end{array}$ & $\begin{array}{c}\text { Per capita } \\
\text { resto- ingesta (g) }\end{array}$ & $\begin{array}{c}\text { Consumo per } \\
\text { capita (g) }\end{array}$ & $\begin{array}{c}\text { Índice resto- } \\
\text { ingesta (\%) }\end{array}$ \\
\hline $28 / 03 / 2018$ & 277 & 15,50 & 56,0 & 627 & 8,92 \\
\hline $\begin{array}{c}29 / 03 / 2018 \\
\text { a }\end{array}$ & & & FERIADO & & \\
$30 / 03 / 2018$ & & & & & \\
\hline $02 / 04 / 2018$ & 189 & 9,80 & 51,9 & 566 & 9,17 \\
\hline $03 / 04 / 2018$ & 299 & 15,30 & 51,2 & 607 & 8,43 \\
\hline $04 / 04 / 2018$ & 308 & 11,70 & 38,0 & 545 & 6,96 \\
\hline $05 / 04 / 2018$ & 237 & 15,90 & 67,1 & 670 & 10,02 \\
\hline $06 / 04 / 2018$ & 245 & 9,50 & 38,8 & 655 & 5,92 \\
\hline MÉDIA & $\mathbf{2 6 7}$ & $\mathbf{1 1 , 5}$ & $\mathbf{4 3 , 3}$ & $\mathbf{5 8 6 , 5}$ & $\mathbf{7 , 4}$ \\
\hline
\end{tabular}

Fonte: Autor (2018).

Houve uma diminuição da média de resto-ingesta per capita de $9,6 \mathrm{~g}$, em relação a $1^{\text {a }}$ etapa, e um aumento de $0,2 \mathrm{~g}(0,46 \%)$ na $3^{\circ}$ etapa em relação a $2^{\circ}$, porém este aumento se mostra insignificante, não interferindo no percentual de redução, que foi de $18 \%$.

Na Figura 12 é possível verificar a redução da média do índice restoingesta nas três etapas do estudo, sendo na etapa de observação de $52,9 \mathrm{~g}$, na segunda, onde ocorreram as estratégias de educação ambiental 43,1 g e terceira, na qual foi feito novo diagnóstico de 43,3 g. Analisando as Tabelas 3 , 4 e 5, é possível perceber essa redução da média ao longo do estudo, referente ao resto ingesta $(\mathrm{kg})$, que inicialmente era de $15,08 \mathrm{~kg}$ e no último período foi de $11,5 \mathrm{~kg}$. Porém, notou-se que a maior redução da média do resto-ingesta em kg ocorreu durante a aplicação das ações de educação ambiental contra o desperdício que foi $9,9 \mathrm{~kg}$.

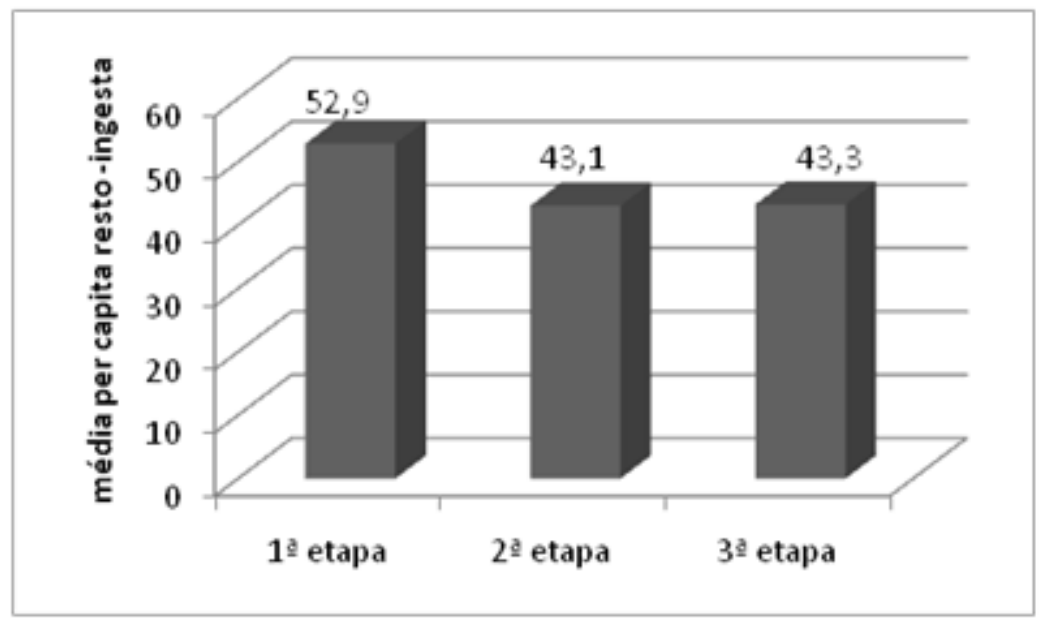

Figura 12: Média per capita resto-ingesta por etapa.

Fonte: Autor (2018). 
Através do resto-ingestão pode-se calcular a quantidade de pessoas que poderiam ser alimentadas. Foi possível identificar a redução deste índice, pois na primeira etapa da pesquisa a média era de 27 pessoas, já na segunda etapa diminuiu para 17 , porém na terceira aumentou para 20 , entretanto se manteve menor que a do início da pesquisa.

Viana et al. (2016), apresentou em um estudo sobre avaliação de restoingestão após campanha de conscientização em uma UAN em Porto Velho $\mathrm{RO}$, onde a média do peso do resto reduziu de $1,02 \mathrm{~kg}$ na semana antes da realização da campanha, para $920 \mathrm{~g}$ durante a campanha, significando uma redução de $9,8 \%$ no resto total que era jogado fora. O percentual de restoingestão diminuiu na média de $3,0 \%$ para $2,6 \%$ e o resto per capita de $20 \mathrm{~g}$ para $10 \mathrm{~g}$.

No início de sua pesquisa sobre a avaliação do per capita resto-ingesta em uma UAN em Anápolis - GO, Machado et al. (2012), obteve uma média do per capita de resto-ingesta de $60,9 \mathrm{~g}$, após a intervenção educacional, a média ficou em 55,3g. Comparando-se o resto-ingesta antes e após a campanha contra o desperdício de alimentos, houve redução de 9,8 \%, equivalente a 5,6g.

Já Pimentel et al. (2006) em um trabalho voltado para educação ambiental como redução de resíduos em um restaurante universitário em Piracicaba, apresenta redução do desperdício de alimentos por refeição de $64 \mathrm{~g}$ per capita para $54,8 \mathrm{~g}$, o equivalente a $9,2 \mathrm{~g}$ de redução, o que corresponde a $14,4 \%$ de redução do desperdício.

Um estudo realizado por Melo (2017) sobre a avaliação do resto-ingesta no mesmo RA da pesquisa em questão, mostrou valores de per capita com resultados de 46,60g e 46,90g, ainda um pouco acima do limite recomendável por Vaz (2006).

De acordo com Augustini et al. (2008), devem ser criadas medidas estratégicas para o combate ao desperdício alimentar em Unidades de Alimentação e Nutrição, como campanhas de conscientização direcionadas aos clientes, mostrando que eles fazem parte do processo de redução do desperdício e que devem controlá-lo e reduzi-lo.

\section{Conclusão}

A implementação da educação ambiental como estratégia para a redução do resto-ingesta se mostra eficiente, e pôde ser aplicada através de ações e atividades que contribuíram para a minimização do per capita de restoingesta, levando os usuários do RA a despertarem interesse pelo meio ambiente, sensibilizando-os sobre os impactos negativos ocasionados por esse ato, fornecendo informação e conhecimento às pessoas, como por exemplo, por meio dos cartazes e reconhecimento de boas atitudes quanto ao não desperdício. 
Conclui-se que a maioria dos valores per capita de resto-ingesta, durante e após a aplicação das estratégias de conscientização, reduziram e permaneceram dentro dos limites estabelecidos na literatura de referência, mostrando assim, a importância que a educação ambiental tem para minimizar o problema do desperdício de alimentos.

A avaliação do novo diagnóstico, na última etapa, por meio da análise dos dados, se mostrou satisfatória, visto que o índice de redução da média per capita de resto-ingesta manteve-se constante, com 18\%, havendo a necessidade de continuidade das ações para uma maior redução deste índice, até que não se tenha descarte de restos de comida no lixo, chegando próximo de $0 \%$. Requer também uma maior atenção da empresa para estar sempre buscando práticas ambientais que auxiliem na melhoria do ambiente. Este trabalho contribuiu positivamente para o incentivo as práticas ambientais do RA e para a conscientização ambiental dos comensais que o frequentam.

Para trabalhos futuros podem ser utilizadas novas estratégias de maneira permanente, e que possibilitem comparar também os dados de redução obtidos no jantar. Além disso, podem ser realizados trabalhos que envolvam as demais variáveis como Sobra Limpa (SL) e Sobra Suja (SJ), além da sensibilização dos próprios colaboradores da Unidade de Alimentação e Nutrição em questão.

\section{Agradecimentos}

Ao Instituto Federal do Ceará - campus Sobral e ao Restaurante Acadêmico do Campus de Sobral pela oportunidade de realizar este trabalho, juntamente com 0 apoio da sua equipe.

\section{Referências}

AUGUSTINI, V. C. M.; KISHIMOTO, P.; TESCARO, T. C. ALMEIDA, F. Q. A. Avaliação do índice de resto-ingesta e sobras em unidade de alimentação e nutrição (UAN) de uma empresa metalúrgica na cidade de Piracicaba/SP. Rev. Simbio-Logias. v.1, n.1, mai., 2008.

BRASIL. Resolução CFN No 380 de 2005. Conselho Federal dos Nutricionistas. 2005. 45p.

BRASIL. Lei $n^{\circ} 9.795$, de 27 de Abril de 1999. Presidência da República Casa Civil. Disponível em: <http://www.planalto.gov.br/ccivil 03/leis/ L9795.htm> Acesso em: 28 out. 2017, 11h06min.

CASTRO, M. D. A. S.; OLIVEIRA, L. F.; PASSAMANI, L. Resto-Ingesta e aceitação de refeições em uma Unidade de Alimentação e Nutrição. Revista Higiene Alimentar, São Paulo, v.17, n.114/115, p.24-28, 2003. 
FAO. Desperdício de Alimentos tem consequências no clima, na água, na terra e na biodiversidade. 2013. Disponível em: <http://www.fao.org.br/daccatb.asp > Acesso em: 18 mar. 16h04min.

GIL, A. C. Como elaborar projetos de pesquisa. $3^{\circ}$ ed. São Paulo: Atlas, 1996. 159p.

MACHADO, C. C. B.; MENDES, C. K.; SOUZA, P. G.; MARTINS, K. S. R.; SILVA, K. C. C. Avaliação do índice de resto ingesta em uma unidade de alimentação e nutrição institucional de Anápolis - GO. Ensaios e Ciência: Ciências biológicas, agrárias e da saúde. vol. 16 nº 6. p 151-162. 2012.

MELO, R. P. Avaliação do índice de resto ingesta em um restaurante universitário da cidade de Sobral - CE. 2017. 32p. Trabalho de Conclusão de Curso (Graduação em Tecnologia de Alimentos) - Instituto Federal de Educação, Ciência e Tecnologia, Sobral, 2017.

MULLER, P. C. Avaliação do desperdício de alimentos na distribuição do almoço servido para os funcionários de um hospital público de Porto Alegre RS. 2008. 33p. Trabalho de Conclusão de Curso (Graduação em Nutrição) Universidade Federal do Rio Grande do Sul, Porto Alegre, 2008.

PIMENTEL, B. C.; MORAIS, T. G.; SCOTTON, K. ; MEIRA, A. M. Educação Ambiental voltada para a Minimização de Resíduos no Restaurante Universitário campus "Luiz de Queiroz"- USP (Piracicaba). 2006.

RUIZ LANNA, N. B. Desperdício de alimentos: até quando? Revista Digital Simonsen, v. 5, nํ5, Rio de Janeiro, nov. 2016..

SILVA, C. R. O. Metodologia e organização de projeto de pesquisa (Guia prático). Centro Federal de Educação Tecnológica, maio 2004.

VAZ, C. S. Restaurantes - Controlando custos e aumentando lucros. Brasília: LGE, 2006. 196 p.

VIANA, K. L. S.; SOUZA, A. L. M. Avaliação do índice de resto ingestão, antes e durante uma campanha educativa, em unidade de alimentação e nutrição (UAN), Porto Velho - RO. Revista Eletrônica do UNIVAG, n 14. 2016. 